\title{
INTERACTIVE SIMULATION EDUCATION OF NURSES
}

\author{
G. Petrova*, V. Lalova, E. Merdjanova \\ Department of Nursing, Faculty of Public Health, Medical University of Plovdiv, Plovdiv, \\ Bulgaria
}

\begin{abstract}
INTRODUCTION: Nursing education in a medical simulation centre allows interactive recreation of a clinical situation without exposing the patient at risk, and at the same time stimulating the critical thinking of students. THE PURPOSE of the present study is to analyze the curricula regarding the main subjects for the nursing specialty at the Faculty of Public Health (FPH) - Plovdiv, by establishing the degree of the educational content, which is appropriate for teaching in a medical simulation training centre. MATERIAL OF METHODS: Using the sociological method of document analysis, in the summer semester of 2017/18, an analysis was made of the educational content of two compulsory subjects included in the nursing curriculum of FPH at MU-Plovdiv: Philosophy and introduction to nursing care. Theoretical foundations - 195 academic hours; Practical foundations of the nursing care - includes 14 modules of specialized subjects - 660 academic hours. RESULTS: In case of analysis of the contents of the subjects forming theoretical knowledge and practical skills in the future nurses, it was found out that both subjects have thematic units which are appropriate: measurement and entry of pulse, breading and blood pressure; rules and equipment for the performance of different types of manipulations; feeding of a seriously ill patient with a probe; provision of a permanent peripheral intravenous route; obligations of the nurse while taking material for laboratory tests; obligations of the nurse while taking blood; preparation of the patient for ECG; catheterization, etc. CONCLUSION: The training in a Medical simulation training centre (MSTC) could find its place immediately after the theoretical training but it must precede the practical training involving a patient.
\end{abstract}

Key words: Health care, Medical simulation training center, Training of nurses.

\section{INTRODUCTION}

Nursing education in a medical simulation centre allows interactive recreation of a clinical situation without exposing the patient at risk, and at the same time stimulating the critical thinking of students.

The changes in the medical education and culture have reduced the possibilities for perception of traditional training when it refers to building up clinical skills. Maran NJ and Glavin RG (2003) describe simulation as an interactive educational technique enabling interactive recreation of a clinical situation without exposing the patient at risk (1).

Notwithstanding the fact that in the last decade there are wide discussions regarding the

\footnotetext{
*Correspondence to: Assoc. Prof. Gergana Petrova, PhD, Department of Nursing, Faculty of Public Health, Medical University of Plovdiv, blvd. "Vassil Aprilov" 15a, Plovdiv-4002, Bulgaria; $e$ mail: gkpg21@yahoo.com; GSM: +359898468296
}

advantages and disadvantages of the simulation training Elliott K., Marks-Maran D., Bach R. (2018) and at this stage they define it as an innovation in the nursing education, which receives a positive feedback from the students (2).

According to Borg Sapiano A., Sammut R., Trapani J (2018), virtual simulation is an efficient training tool, which increases the knowledge and efficiency in the patient's care. The authors express an opinion that virtual simulation of rare conditions must be a key component in the nursing education, in order to prepare the students to manage complex situations in their future practice (3).

The results of a research carried out by LevettJones T., Lapkin S., Govind N., Pich J., Hoffman K., Jeong SY., Norton CA., Noble D., Maclellan L., Robinson-Reilly M., Everson N. (2017), show the capacities of the simulation education for its positive influence 
on the compassion and empathy of the students towards disabled people. The authors recommend similar studies with other patients (4).

The application of simulated education (Bliss M, Aitken LM., 2018) is also reviewed as a strategy of the nurses, for increase in their awareness of deteriorating patients. According to the students, their knowledge are transferred to the clinical practice and all this contributes to the patient care (5).

THE PURPOS of the present study is to analyze the curricula regarding the main subjects for the nursing specialty at the Faculty of Public Health (FPH) - Plovdiv, by establishing the degree of the educational content, which is appropriate for teaching in a medical simulation training centre.

\section{MATERIAL AND METHODS}

Using the sociological method of document analysis, in the summer semester of 2017/18, an analysis was made of the educational content of two compulsory subjects included in the nursing curriculum of FPH at MU-Plovdiv: Philosophy and introduction to nursing care. Theoretical foundations - 195 academic hours; Practical foundations of the nursing care includes 14 modules of specialized subjects 660 academic hours.

\section{RESULTS AND DISCUSSIONS}

The review of the literature in this matter allowed us to describe some of the main features of the simulation education:

- It is implemented in a safe or harmless educational medium, creating an opportunity for a feedback from the students; teamwork abilities are created, which are essential in the area of health care (6).

- the work with hi-tech increases the selfconfidence of the students, independent learning, self-development which leads to autonomy of the student, increases the skills for work in a clinical environment and refines the actions of the future specialists (7).

- errors with patients during education are avoided (8).

- the stay for training in a clinical environment is reduced (9).

- it is successfully implemented at all levels of education, including in the on-going (10).

In case of analysis of the contents of the subjects forming theoretical knowledge and practical skills in the future nurses, it was

\section{PETROVA G., et al.}

found out that both subjects have thematic units which are appropriate:

- measurement and entry of pulse, breading and blood pressure;

- rules and equipment for the performance of different types of manipulations;

- feeding of a seriously ill patient with a probe;

- provision of a permanent peripheral intravenous route;

- obligations of the nurse while taking material for laboratory tests; obligations of the nurse while taking blood; preparation of the patient for ECG;

- catheterization, etc.

\section{CONCLUSION}

In our previous study Petrova, G., Ts. Miteva, N. Kantardzhiev (2011) the concept that there is resistance which is available in some of the lecturers, however the application of computer simulations as a stage of the education at the Medical Universities preceding the work with patients in a simulated clinical environment is of importance for the building of professional skills in the students: manipulative, communicative, personal, etc. (11).

A compulsory element of the nursing education in Bulgaria is the training with the help of a patient. The attitude towards the patient in the health care education is very preserving and humane. The training in a Medical simulation training centre (MSTC) could find its place immediately after the theoretical training but it must precede the practical training involving a patient. After completion of the lecturing, exercise on a simulated patient should be carried out in a simulation centre under the control of a lecturer. Only after completion of this second stage the students would be able to be trained in an actual hospitable environment and to apply in practice the theoretical knowledge and practical skills to a patient.

\section{REFERENCES}

1. Maran NJ и Glavin RG., Low - to highfidelity simulation - a- continuum of medical education? Med Educ, Nov; 37 Suppl 1:22-8, 2003.

2. Elliott K., Marks-Maran D., Bach R., Teaching student nurses how to use electronic patient records through simulation: A case study. Nurse Education in Practice, May; 30:7-12, 2018. doi: 10.1016/j.nepr.2018.02.003. Epub 2018 Feb 7.

3. Borg Sapiano A., Sammut R., Trapani J., The effectiveness of virtual simulation in 
improving student nurses' knowledge and performance during patient deterioration: A pre and post test design. Nurse Education Today, Mar; 62:128-133, 2018. doi: 10.1016/j.nedt.2017.12.025. Epub 2017 Dec 29.

4. Levett-Jones T, Lapkin S, Govind N, Pich J, Hoffman K, Jeong SY, Norton CA, Noble D, Maclellan L, Robinson-Reilly M, Everson N., Measuring the impact of a 'point of view' disability simulation on nursing students' empathy using the Comprehensive State Empathy Scale, Nurse Educ Today, .Dec;59:75-81, 2 017. doi: 10.1016/j.nedt.2017.09.007. Epub 2017 Sep 20.

5. Bliss M, Aitken LM., Does simulation enhance nurses' ability to assess deteriorating patients? Nurse Educ Pract. Jan;28:20-26, 2018. doi: 10.1016/j.nepr.2017.09.009. Epub Sep 12.

6. Beaubien JM, Baker DP., The use of simulation for training teamwork skills in health care: how low can you go? Qua . education with high-fidelity human patient
PETROVA G., et al. simulation, Nurse Education. Jan -Feb; 29 (1):25-30, 2004.

7. Petani LA., Enhancing clinical practice and education with high-fidelity human patient simulation. Nurse Education, Jan -Feb; 2,9 (1):25-30, 2004.

8. Ziva, Wope PR, Small SD, Glick S., Simulation-based medical education: an ethical imperativa. Acta Med. Aug; 78 (8):783-8, 2003.

9. Weis PA, Guyton - Simmons J. A computer simulationfor teaching critical thinking skills. Nurse Educ, Jan-Feb; 29 (1):25-30, 2004.

10.Nehring WM, Lashley FR. Current use and opinions regarding human patient simulations in nursing education: an international survey. Nurs Educ. Perspect. Sep-Oct; 25 (5):244-8, 2004.

11.Petrova, G., Ts. Miteva, N. Kantardzhiev, Application of computer simulations in medical education, Innovative practices in education, A collection of scientific studies and articles, University Publishing House, Blagoevgrad, 227-230, 2011. 